\title{
El testimonio y sus aporías
}

\author{
Luis ARAGÓN GONZÁLEZ \\ UNED \\ escrituraeimagen@filos.ucm.es
}

\section{Resumen}

Derrida, a lo largo de su dilatada obra, ha llevado a cabo un riguroso trabajo de deconstrucción de algunas cuestiones que han conformado el discurso de la tradición metafísica. En este artículo nos detendremos en el significado filosófico del testimonio que porta el testigo. Una reflexión que, si bien se enmarca en lo que desde los años noventa se ha denominado "pensamiento de lo imposible", se deja rastrear desde sus primeras publicaciones.

Palabras clave: Derrida, deconstrucción, testimonio, testigo, acontecimiento.

\begin{abstract}
Throughout his vast production, Derrida carried out a strict work of deconstruction of some aspects which have made up the thesis of metaphysical tradition. The aim of this article is to point out the philosophical meaning of the testimony provided by the witness. A reflection which, even if included in what was called "thinking the impossible" in the 90 s, we can trace back to his very first publications.
\end{abstract}

Key words: Derrida, deconstruction, testimony, witness, event.

1. Derrida nos ha enseñado a leer y escribir de otro modo, a dirigir nuestra atención hacia aquellas temáticas excluidas de la metafísica, constituyendo este rechazo no un episodio accidental, una desviación corregible, una disfunción reparable, 
sino el tejido mismo de la historia de la filosofía. Siempre entre líneas, con una sonrisa burlona, buscando identificar esos puntos de fuga en donde se consuma el fracaso totalizador y tranquilizante de la filosofía, la plena presencia, así bucea Derrida en los textos heredados. La deconstrucción trabaja desde las entrañas de la tradición para traicionarla, evidenciando lo precario de sus cimientos e introduciendo un principio de ruina en la maltrecha arquitectónica de la razón. A menudo insiste Derrida en que la deconstrucción que él practica no le sobreviene al texto "desde el exterior, un buen día; está siempre en obra en la obra"1. La metafísica y la deconstrucción se quieren y se reclaman: no hay la una sin la otra. Unidas como dos hermanas siamesas. Se trata, pues, de repensar la metafísica de la manera más íntima posible para certificar cómo está en deconstrucción y, a su vez, cómo la deconstrucción se alimenta de la metafísica. No cabe, por lo tanto, sino hablar de una fecunda fidelidad de la deconstrucción hacia la filosofía, nunca de una pura y simple destrucción, de una actitud nihilista en relación con la herencia ${ }^{2}$, sino, más bien, de una aguda y penetrante mirada preocupada por sacar a un primer plano a aquellos pérfidos huéspedes los cuales, a pesar de todos los denodados esfuerzos por eliminar de la filosofía, por sustraer a la reflexión, estaban ahí, incomodando con su sola presencia, agazapados, entre bastidores. La deconstrucción se nos presenta, entonces, como un desplazamiento estratégico hacia un conjunto de temas juzgados menores, secundarios, irrelevantes, en definitiva, insignificantes.

El texto que conforma la tradición se transforma, a ojos de Derrida, en un campo de batalla en el que entran en liza fuerzas diversas que pugnan y combaten entre sí. A muerte. Podemos decir que las estrategias deconstructivas-siempre plurales e irreductibles a un programa exportable a situaciones diferentes; de otro modo la deconstrucción se reduciría a una especie de recetario insensible a los contextos y a las problemáticas, sub specie aeternitatis, ajena a las peculiaridades de cada singularidad, de cada firma- son una manera de habitar la cultura filosófica para descubrir esos huecos en los que acontece un momento de quiebra. Además, que la deconstrucción se desmarque de toda práctica metódica, que busque abrir sendas no trilladas, que sueñe con una palabra inaugural tan novedosa como desconocida, intraducible, poética, inesperada, es lo que la liga a un pensamiento de lo imposible - donde habremos de incluir el testimonio.

Entre las figuras para pensar la deconstrucción de la metafísica que Derrida ha privilegiado a lo largo de los años, se encuentra, por citar sólo dos, la escritura y la espectralidad. A esta lista añadiremos la del testigo. Lo que nos proponemos en

\footnotetext{
${ }^{1}$ Derrida, J.: Mémoires - pour Paul de Man. Paris, Galilée, 1988, p. 83.

2 "Amo mucho todo lo que deconstruyo a mi manera, los textos que deseo leer desde este punto de vista deconstructivo son textos que amo" (Levesque, CL. y McDonald, CH., éds.: L'oreille de l'autre. Otobiographies, transferts, traductions. Textes et débats avec Jacques Derrida. Montréal, VLB, 1982, p. 119).
} 
estas páginas es darle la palabra al testigo, dejarnos conducir por él, prestarle nuestro oído. Esta desconsideración de la filosofía hacia el testimonio -actitud ésta que contamina igualmente la investigación histórica ${ }^{3}$-, su desvalorización recurrente, ha de servirnos como piedra angular para mostrar la deconstrucción del discurso filosófico en su búsqueda de objetividad y plenitud.

2. Acabamos de señalar la escasa recepción que el testigo ha tenido en la historia del pensamiento. Los filósofos no parecen haberle otorgado ninguna importancia intelectual. Es en el discurso jurídico o literario en donde el testigo habría encontrado asiento. La razón de este desinterés responde a la naturaleza misma del testimonio. Aquello que relata el testigo es su experiencia íntima, lo que él y sólo él en primera persona ha presenciado - ese es su secreto; una verdad que no puede ser sino de carácter particular, subjetivo o parcial entrando en contradicción con la aspiración universalista que anima a la filosofía. Mientras que en todo testimonio nos encontramos con una verdad transida de subjetividad, la filosofía tiene como voluntad alcanzar una transparencia sin claroscuros. De lo que el testigo testifica, en primer término, es de su destierro o expulsión del logos. Allí donde habla el testigo, calla la razón. Lo que está en juego en este olvido del testigo es una teoría de la verdad que vincula ésta con la objetividad de las ideas o con la presencia diáfana de sí en la autoconciencia. El testigo compromete un conjunto de valores asociados a la noción de verdad ${ }^{4}$ como pueda ser el de evidencia, objetividad e intersubjetividad. Por todo ello, la inclusión del testimonio en la nómina de problemas filosóficos va de la mano de una nueva concepción epistemológica, de una reinterpretación de la noción de verdad. Darle la palabra al testigo y escuchar lo que tenga que decirnos supondrá desmarcarse o tomar distancia de la filosofía, constituyendo esta apuesta un gesto antifilosófico a no ser que, y esta será nuestra hipótesis de trabajo, el testimonio no sea tan extraño a la filosofía. De ser válida esta suposición, aquel a quien se habría querido circunscribir al terreno jurídico o al mundo literario, al estrado o

\footnotetext{
3 Se pueden considerar paradigmáticas las palabras con que Raul Hilberg, voz insustituible para el conocimiento del exterminio judío, abre su impresionante libro La destrucción de los judios europe$o s$ : "abundaban, por el contrario, los relatos de los supervivientes. Contenían información valiosa sobre las reacciones de las víctimas, pero no iluminaban la evolución de los acontecimientos [...]. Me di cuenta de que, sólo por esta razón, una historia global debía basarse, en primer lugar, en los registros de aquellos que habían iniciado o puesto en práctica las medidas antijudías" -la cursiva es nuestra- (Hilberg, R.: La destrucción de los judios europeos. Madrid, Akal, 2005, p. 10). El historiador debe, pues, dejar de lado, en su empeño por construir una historia global, la frágil mirada de los sobrevivientes, incapaces de ofrecer esa visión objetiva de las cosas a que aspira el saber histórico.

4 "La filosofía [...] quiere situarse en un lugar donde todo lo que se dice y se hace sea pensable, teorizable, en definitiva, dominable. Es el lugar del dominio absoluto, el proyecto del saber absoluto. Pero aunque esto no toma esta forma expresa más que en Hegel, el saber absoluto es la verdad del proyecto filosófico" (Derrida, J.: Points de suspension. Entretiens. Paris, Galilée, 1992, pp. 149-150).
} 
a la ficción, habría parasitado desde el principio la filosofía, como su sombra, su más irritante invitado.

Entre aquellos raros pensadores 5 que han reflexionado acerca del significado filosófico del testigo y del testimonio está el pensador francés Jacques Derrida.

La palabra 'testigo' en latín tiene dos términos. En primer lugar, testigo se dice testis, aquel que como 'tercero' -terstis- asiste a un proceso entre dos. Testigo sería quien en calidad de espectador y, por lo tanto, desde su neutralidad, da cuenta de unos hechos. Vemos que el motivo de la presencia es central toda vez que el testigo se adelanta para testificar, bajo palabra, lo que vio u oyó, aquello que presenció sin intervenir en el devenir de los acontecimientos pretéritos. En segundo lugar, hay en latín otra palabra que igualmente nombra al testigo: superstes, 'superviviente'. En este caso se trata de quien ha vivido unos episodios de los que puede dar noticia. El superviviente, a diferencia del testigo en tanto que testis, no relata como asistente unos sucesos ajenos a él. Él mismo es quien los ha experimentado y quien puede comunicarlos. Este motivo de supervivencia, este sobrevivir del testigo -superstes-, pone en relación el testamento y el testigo. Este como depositario de una vivencia personal se presenta como heredero, guardián o garante de una herencia recibida, de un testamento.

3. Esta idea de supervivencia, más allá de su vinculación etimológica con el testigo, recorre la deconstrucción de Derrida. Él mismo escribe que "todos los conceptos que me ayudaron a trabajar, particularmente el de la huella o lo espectral, estaban vinculados al 'sobrevivir', como dimensión estructural y rigurosamente originaria"6. Veámoslo.

Frente a la concepción clásica de la escritura como secundaria, suplemento, representante de la voz -logofonocentrismo-, Derrida desarrolla una noción de huella que no plantea una simple inversión del par palabra/escritura, dando la vuelta a un esquema metafísico, sino una generalización de la escritura que recibirá el nombre de gramatología. La huella que afecta a todo signo se piensa como un proceso constante de reenvíos cuya consecuencia es el rechazo del mito de un comienzo cero, de una verdad primera, de un significado trascendente que detenga y dirija la

\footnotetext{
5 Cabe recordar que Reyes Mate en Memoria de Auschwitz recoge las ideas que sobre la noción de testigo han elaborado Frank Rosenzweig, Enmanuel Levinas y Walter Benjamin (Mate, R.: Memoria de Auschwitz. Madrid, Trotta, 2003, pp. 172-184). Por otro lado, el libro de Agamben, Lo que queda de Auschwitz, con todo lo discutible que sean algunas de sus tesis vertebradoras, como han mostrado Mesnard y Kahan en Giorgio Agamben à l'épreuve d'Auschwitz, discutiendo palabra por palabra el texto de aquél, presenta el indudable mérito de haber traído la figura del testigo al terreno de la filosofía. Haber arrancado al testigo de las manos del derecho y de la literatura para constituirse en objeto propio de la meditación filosófica es una de las líneas que su fructífero trabajo ha seguido.

6 Derrida, J.: Apprendre à vivre en fin. Entretien avec Jean Birnbaum. Paris, Galilée, 2005, p. 26.
} 
cadena significativa. Lo que la huella pone de manifiesto es que no hay origen 7 , que todo origen pasa por la huella dejada por otro elemento del que lleva su marca. Un sistema de signos es un tejido de diferencias sin punto de partida o de llegada. La huella es irreconciliable con las ideas de procedencia y de destino. Si la escritura ha sido pensada como 'significante de significante' -fónico-, la respuesta derridiana consistirá en extender a todo lenguaje esta trama referencial de modo que ningún signo se agota en sí mismo. El significado está ya en posición de significante. El lenguaje se constituye, pues, en un juego de diferencias-différance-, donde el otro sobrevive. El remitir uno a otro, el dar testimonio del otro, la herencia con que se carga, el portar la huella de otra huella, todo ello es la plasmación de la lógica del superviviente.

En cuanto al otro espectral, el texto de referencia obligada es Spectres de Marx. Tomando como punto de arranque el comienzo del Manifiesto comunista, "un espectro se cierne sobre Europa: el espectro del comunismo"8, Derrida va a desarrollar una lectura ante todo política de la noción de espectralidad, tan unida a la de supervivencia. Entre el espectro y la anterior lógica de la huella hay más continuidad que ruptura. Si la huella ni está presente ni ausente, otro tanto habría que decir del espectro: ni vivo ni muerto, sobreviene, sobrevive. No podemos decir que sea ni que no sea. Viene pero no llega. Pasa, nos frecuenta, nos visita a destiempo, en un tiempo dislocado. No sabemos si cuando nos asedia viene del pasado o regresa del futuro. Un espectro - revenant- es un (re)aparecido que viene sin venir, sin llegar a presentarse 'en carne y hueso' pues el espectro "no es ni sustancia, ni esencia ni existencia, no está nunca presente como tal"9. El ahi del espectro es que no está $a h i$, carece de presente aunque aparente presentarse, haciendo acto de presencia en un presente sin presente. Esta fuerza de ruptura del espectro respecto al principio de identidad - ni, ni- y a la linealidad del tiempo - presente, pasado y futurolo convierte en un personaje molesto para la filosofía. Frente al gesto platónico que configura el marco del pensamiento ontológico de occidente con pares jerarquizados, Derrida plantea un pensamiento nuevo que denomina fantología (hantologie) y que gira sobre la noción de espectralidad. Si la filosofía no cree en los espectros es porque sus categorías son insuficientes para apresar la aparición furtiva de los (re)aparecidos. Pensar la espectralidad nos obliga a sacudirnos los caducos esquemas que han presidido la historia de la filosofía.

\footnotetext{
7 "La huella no es sólo la desaparición del origen, quiere decir [...] que el origen mismo ni siquiera ha desaparecido, que nunca se ha constituido, en contrapartida, más que por un no-origen, la huella que deviene de este modo el origen del origen" (Derrida, J.: Marges - de la philosophie. Paris, Minuit, 1972, p. 44).

8 Marx, C.: El manifiesto comunista. Madrid, Endymión, 1987, p. 41.

9 Derrida, J.: Spectres de Marx. Paris, Galilée, 1993, p. 14.
} 
4. Antes de centrarnos en el testimonio como tal habría que empezar sospechando que se pueda determinar algo así como una esencia, una identidad estable, un concepto puro de testimonio, libre de toda contaminación extraña. Como iremos viendo, la palabra del testigo exige como condición de posibilidad su imposibilidad, esto es, el asedio de aquello mismo que lo pone en cuestión y lo conduce a la ruina: el perjurio o la mentira. Si olvidamos esta advertencia preliminar, todo discurso que pretenda aislar un contenido propio en el testimonio estará condenado al desastre. Dicho esto, tampoco hay que concluir que no exista diferencia alguna entre testimoniar, mentir y demostrar. Que los límites no sean tan nítidos como cabría esperar y que la frontera entre los mismos sea permeable, transitable o porosa no supone que no haya que hacer un esfuerzo por diferenciar teóricamente entre cada uno de los términos.

Una primera referencia al testimonio en la obra derridiana, más concretamente al testamento, a la escritura en tanto que testamento ${ }^{10}$, la encontramos en De la grammatologie cuando leemos que "todo grafema es de esencia testamentaria"11. En un texto posterior, Marges - de la philosophie, profundiza Derrida en la complejidad de esa frase que hace alusión a la doble mortalidad que afecta al autor y al lector.

Un signo escrito se disocia, en primer término, del receptor. Cuando escribimos nos dirigimos a alguien que no podemos determinar, por mucho que queramos individualizarlo. Desconocemos a dónde irá a parar el texto. Que éste nunca llegue a su destino no se debe a que se extravíe en el camino a causa de alguna desgracia inesperada sino porque su diseminación lo aleja de todo trayecto definido o definitivo, de toda dirección trazada de antemano. No se sabe a priori, es imposible preconizar, cuál será la fortuna de un texto, en qué manos caerá y cómo será leído. La ausencia de un destinatario empíricamente determinable no es, pues, temporal sino estructural. Forma parte del signo deambular sin rumbo fijo. Una ceguera que no es, como pudiera sugerirse, un obstáculo para la legibilidad del texto sino que es, más bien, su condición de posibilidad. Un texto no existe sino repitiéndose y en cada vuelta, a veces bajo la forma de una revuelta, es ya otro, no siendo nunca el mismo aun tratándose del mismo. Esta conjunción de repetición y diferencia queda recogida en la palabra iterabilidad, compuesta de itera que procede del sánscrito "otro" y que vincula "la repetición a la alteridad"12. Este no alcanzar nunca un texto su destino, sus repetidas idas y venidas sin punto de llegada, es lo que permite que no quede agotada la potencialidad inventiva de la escritura. En este sentido, apunta

\footnotetext{
10 “¿Y por qué la cuestión del testimonium no es otra que la del testamentum, de todos los testamentos, es decir, del sobrevivir en el morir?" (Derrida, J.: "Poétique et politique du témoignage" en la revista Prosopopeya (Valencia), no 1, otoño/invierno, 1999, p. 116).

11 Derrida, J.: De la grammatologie. Paris, Minuit, 1967, p. 100.

12 Derrida, J.: Marges - de la philosophie, ed. cit., p. 375.
} 
Derrida que "tengo el sentimiento de que, a pesar de siglos de lectura, los textos permanecen vírgenes, plegados en una reserva, todavía por venir"13. La resistencia que provoca cada texto no nace de guardar en su interior una verdad inaccesible, por oculta, en espera de que alguien nos muestre las claves adecuadas para su interpretación. Si todo texto se resiste es porque sencillamente no resulta reapropiable para el lector - tampoco para su emisor.

En segundo término, el signo se desmarca también del autor. Su desaparición física o intencional, es decir, si le sobreviene la muerte o simplemente no refrenda lo suscrito en otro momento, no impide que $s u$ texto -que habría propiamente dejado de pertenecerle, no siendo ya suyo- siga siendo significativo y se dé a leer. El texto cobra vida propia, sobrevive, es capaz de funcionar sin el aliento de su autor, sin su custodia, sin su estrecha vigilancia. Todo escrito se disocia de su emisor, vive a pesar de él, sin él. Por ello, "escribir es producir una marca que constituirá una especie de máquina productora que, a su vez, mi futura desaparición no impedirá que en principio siga funcionando y dando, dándose a leer y a reescribir"14. La escritura, en general todo sistema de signos, se presenta como un testamento, como una última palabra, el anuncio de una muerte anunciada. Cada una de las letras lleva inscrita mi extinción y aniquilación. Mi muerte. Sin este carácter fúnebre de la escritura, extensivo a cualquier signo, perdería su carácter supervivencial. Puede afirmarse, en consecuencia, que cada vez que escribimos estamos haciendo testamento, consignando en cada frase las últimas voluntades en espera, sin esperanza de cierre o de clausura, de que otros sigan abriendo el archivo que ha dejado de pertenecernos.

Es esta orfandad de la escritura la que Platón critica y condena en el diálogo Fedro. Frente a la palabra que puede defenderse de viva voz, la escritura calla, respondiendo siempre lo mismo. Además, "las palabras 'escritas' ruedan por doquier, igual entre los entendidos que entre aquellos a los que no les importa en absoluto, sin saber distinguir a quiénes conviene hablar y a quiénes no"15. La desvalorización platónica de la escritura responde a que está separada de la asistencia del padre, desligada de su origen, circulando de acá para allá sin conocimiento alguno.

Separación del destinatario, del autor y, además, del contexto. Gracias a esta fuerza de ruptura que presenta el signo puede ser citado o injertado, sin que en nada se vea afectada su capacidad generadora de sentido. No hay un contexto definitivo y cerrado que agote la legibilidad de una frase, que impida su devenir maquínico, ya que no existe un marco que sea único, natural, definitivo o suficiente. En consecuencia, "toda marca detenta una fuerza de desapego que no sólo puede liberarla de tal o cual contexto determinado sino que le asegura incluso su principio de inteligi-

\footnotetext{
13 Derrida, J.: Points de suspension. Entretiens, ed. cit., p. 88.

${ }^{14}$ Derrida, J.: Marges - de la philosophie, ed. cit., p. 376.

15 Platon: Fedro, 275e.
} 
bilidad y su estructura de marca, es decir, su iterabilidad (repetición y alteración)" 16 .

En resumen, ya desde sus primeros textos, la cuestión del testamento, de la escritura como testamento que sobrevive al emisor, receptor y contexto, ocupa un lugar importante en la obra de Derrida. Habrá que esperar hasta los años noventa para que irrumpa con fuerza la figura del testigo.

5. La relevancia que adquiere el testimonio en el itinerario de Derrida queda de manifiesto en el hecho de que le dedicase su seminario semanal de la École des Hautes Études en Sciences Sociales (EHESS) entre los años 1992-1995. Asimismo, entre 1997-1999, el tema en torno al que giró su docencia fue el perjurio, indisociable del testimonio, y el perdón. Al margen de este tratamiento sistemático que aún permanece inédito -hay que recordar que la editorial Galilée ha iniciado en 2008 la publicación de los seminarios y cursos que impartió Derrida a lo largo de más de cuarenta años, además de materiales diversos agrupados según fueran manuscritos, escritos a máquina o a ordenador-, en distintos textos, artículos o libros, abordó el testimonio, fuese como cuestión central o al hilo de otras temáticas. En cualquier caso, sí podemos afirmar que el contexto general en el que enmarcar el testimonio y el perjurio, como sucede con el don, el perdón, la hospitalidad, la decisión, la espectralidad, la democracia, la responsabilidad, por ejemplo, sería la deconstrucción en tanto que "cierta experiencia de lo imposible"17. Un conjunto de temas que ha dado pie, con escaso fundamento, a hablar de "un" Derrida más político, lo que se conoce como el "giro ético-político"18 o Kehre y que tantas resistencias provocaba en el propio pensador francés, insatisfecho ante semejante simplificación.

Empezaremos preguntándonos: ¿qué es dar testimonio?, ¿cuáles son los rasgos que caracterizan la palabra del testigo?, ¿podemos diferenciar de un modo claro, sin sombras de duda, entre el testimonio y el perjurio?, ¿se puede saber si alguna vez hubo mentira?, ¿cuál es la relación, si la hay, entre conocimiento y creencia, entre ciencia y fe?, ¿encontramos, en último término, alguna distinción entre testimonio falso o erróneo, y falso testimonio? Veamos, pues, cuáles son los rasgos que conforman el concepto de testimonio. Un camino, el nuestro, que estará sembrado de aporías y en el que habrá que irse abriendo paso. Fatigosamente.

En el testimonio, el testigo no se dirige al otro para informar o hacer saber algo. La verdad del testigo no forma parte de los enunciados constatativos; sus enunciados no tienen un valor cognoscitivo. Eso no es lo esencial. En el testimonio se obra

\footnotetext{
16 Derrida, J.: Politiques de l'amitié. Paris, Galilée, 1994, p. 244.

17 Derrida, J.: Psyché. Inventions de l'autre. Paris, Galilée, 1998, p. 27.

18 "Yo soy más sensible a la continuidad que a lo que algunos llaman, sobre todo en el extranjero, el 'political turn' o el 'ethical turn' de la deconstrucción" (Derrida, J.: Papier Machine. Paris, Galilée, 2001, p. 386).
} 
o se hace la verdad. Lo propio del testimonio no está en la verdad expuesta, cuya exposición al posible error o equivocación no se puede excluir de antemano; no está en lo que se dice, en el contenido objetivo, viciado de subjetividad, sino en lo que se hace al decir, esto es, en el compromiso que adquiere el testigo. Por esta razón, la palabra testimonial se incluye, siguiendo con la clasificación de Austin, en la clase de los enunciados realizativos.

Esta dimensión performativa inscrita en todo testimonio, este 'hacerse la verdad', Derrida la conecta con las reflexiones de san Agustín en su libro Las confesiones a propósito de la confesión. En ambos casos, en la confesión y en el testimonio, la verdad se realiza. La pregunta clave que formula el obispo de Hipona es: "¿por ventura, Señor, siendo tuya toda la eternidad, ignoras las cosas que te digo, o ves en el tiempo lo que se ejecuta en el tiempo? Pues ¿por qué hago relación de tantas cosas? No ciertamente para que las sepas por mí sino que excito con ellas hacia ti mi afecto y el de aquellos que leyeren estas cosas, para que todos digamos: grande es el Señor y laudable sobremanera. Ya lo he dicho y lo diré: por amor de tu amor hago esto"19. En caso de que la confesión o el testimonio consistiesen en exponer, desvelar o enunciar un contenido determinado, estaríamos alejándonos del nudo central. Lo que nos enseña este filósofo es que, en la confesión y por extensión en el testimonio, se obra o hace la verdad20; algo ocurre que no se reduce a transmitir una verdad sino que se produce una transformación personal. No hay confesión, por lo tanto, sin conversión y arrepentimiento, sin la modificación de uno mismo. Por eso, la verdad de la confesión no está en la 'verdad' dicha o contada, en la historia narrada, sino en la relación establecida con uno mismo y con el otro. Lo singular de la confesión no es que en ella se dice la verdad sino que en ella, a través de la palabra, se hace la verdad. De un modo análogo, cuando se da testimonio lo primero y fundamental es el crédito pedido al otro, un ¡créeme! que sobrevuela cada una de las palabras.

Quien testimonia pone su palabra por delante, se compromete a decir la verdad, promete decirla a los demás, pidiendo al otro, juez y notario, que le crea más allá de toda prueba o certeza. El carácter secreto y privado del testimonio tiene que ver con la creencia, la fe jurada o el asentimiento incondicional pedido al otro. Por esta razón, el testimonio "no puede sino apelar a un acto de fe" 21 . Pero no basta o no es suficiente con que un testimonio sea creíble, esto es, plausible, convincente o aceptable; antes bien, debe presentarse como algo increíble hasta el punto de que parezca mentira. Un testimonio que fuera sólo creíble, aunque la creencia forme parte

\footnotetext{
19 San Agustín: Las confesiones, libro XI, cap. I. Madrid, BAC, 1968, p. 464.

20 "He aquí que amaste la verdad, porque el que la obra viene a la luz. Quiérola yo obrar en mi corazón, delante de ti por esta mi confesión y delante de muchos testigos por este mi escrito" (Op. cit., libro X, cap. I, p. 390).

21 Derrida, J.: "Poétique et politique du témoignage" en la revista Prosopopeya, ed. cit., p. 131.
} 
consustancial del testimonio, lo invalidaría como testimonio. Por eso, el único testimonio posible y creíble es el testimonio imposible e increíble. Lo increíble no es la refutación del testimonio, es su posibilidad. Este vínculo entre testimonio y credibilidad, lo expresa lúcidamente Primo Levi en el contexto de sus reflexiones acerca del universo concentracionario cuando recoge las palabras de Simon Wiesenthal: "de cualquier manera que termine esta guerra, la guerra contra vosotros la hemos ganado; ninguno de vosotros quedará para contarlo, pero incluso si alguno lograra escapar el mundo no lo creería. Tal vez haya sospechas, discusiones, investigaciones de los historiadores, pero no podrá haber ninguna certidumbre, porque con vosotros serán destruidas las pruebas. Aunque alguna prueba llegase a subsistir, y aunque alguno de vosotros llegara a sobrevivir, la gente dirá que los hechos que contáis son demasiado monstruosos para ser creídos: dirá que son exageraciones de la propaganda aliada, y nos creerá a nosotros, que lo negaremos todo, no a vosotros. La historia del Lager, seremos nosotros quien la escriba"22. Contrariamente a lo que se dice en la cita, la posibilidad misma del testimonio proviene de su carácter inconcebible. Por esta razón, el testimonio de los supervivientes del genocidio alemán no queda cuestionado por la monstruosidad de los hechos acreditados bajo palabra sino, más bien, fortalecido, al menos como testimonio. Si lo que pretendían los nazis era acabar con el testimonio, con la credibilidad de los judíos y de los sobrevivientes en general, la barbarie de los actos cometidos no fue un impedimento para que los supervivientes fuesen creídos. Precisamente la brutalidad de los hechos contados exigía, como contrapartida, su aceptación por un acto de fe como una cosa increíble. La confianza es lo que podía volver creíble lo increíble. Como señala Derrida, "no podemos testimoniar más que de lo increíble; de lo que puede solamente ser creído, de lo que, al exceder la prueba, la indicación, la constatación, el saber, apela solamente a la creencia, por lo tanto, a la palabra dada" 23 .

El testimonio, como le sucede al don, a la promesa, al perdón, a la responsabilidad, a la decisión o a la hospitalidad, motivos todos estos que han determinado el trabajo de Derrida en los últimos años, debe exceder el marco de lo posible, del yo puedo como sujeto soberano, autónomo, libre, para abrirnos a un pensamiento de lo imposible, posible en tanto que imposible: im-posible. Según esto, cuando alguien testimonia aquello que es creíble, aceptable, coherente o asumible, en definitiva, posible, no está testimoniando en sentido radical. Testimoniar sólo de lo intestimoniable. Un testimonio tiene que ser tan increíble que se acepte como un acto de fe. Excesivo hasta el extremo de que haría falta estar loco para creerlo. Excepcional como un milagro. No hay testimonio que no sea inaudito como un acontecimiento - événement. Eso que viene, lo que acontece sin verlo venir, es tan inesperado que

22 Levi, P.: Los hundidos y los salvados. Barcelona, Muchnik, 2001, p. 9. (La cursiva es nuestra).

23 Derrida, J.: Le monolinguisme de l'autre. Paris, Galilée, 1996, p. 41. 
incluso el concepto de espera se vuelve insuficiente. Más allá de toda esperanza, sin relación alguna con la venida imprevista del otro, sin cita previa, sorprendido, la verdad que porta el testigo debe compartir estos mismos rasgos. Más aún, bastaría que fuera posible el testimonio para que se anulase como testimonio; sería suficiente que me creyeran, que mis palabras fueran creíbles, para que se perdiese su carga increíble. El testimonio debe reunir, por lo tanto, dos condiciones que se excluyen entre sí, incompatibles, heterogéneas, pero que, al mismo tiempo, son indisociables. Aunque se repelen, se reclaman o, dicho de otro modo, a pesar del infinito que las separa, se necesitan. Por un lado, un testimonio se refiere al mundo de la creencia, al ámbito de la fe o de la confianza. Esta es la diferencia fundamental entre el testimonio y la prueba, entre testar y demostrar. Por otro lado, que un testimonio sea sólo creíble no satisface la exigencia de infinitud que prescribe: creer lo increíble es el axioma que dicta el testimonio. Al testimoniar lo que es testimoniable, no hay testimonio. No es posible testimoniar sino de lo intestimoniable, de lo imposible. La posibilidad del testimonio es su imposibilidad 24 . ¿Cómo satisfacer ambas condiciones?, ¿cómo escapar de esta aporía, de este double bind o doble vínculo, que habita en el corazón del testimonio?, ¿cómo ser justos con cada uno de los polos? Derrida nos invita a pensar, en una unión imposible, el testimonio finito -creíblee infinito -increíble.

Las palabras anteriores de Wiesenthal plantean además en su radicalidad el proyecto genocida nazi de la desaparición absoluta, del extermino total hasta la eliminación de todo testigo. Borradura de aquellos que pudieran testimoniar de la extinción del otro. La ausencia definitiva de testigo cobra así una nueva luz y pasa a ser interpretada como la realización extrema de una pulsión mortífera. El historiador Vidal-Naquet expresa este mismo pensamiento cuando afirma que los nazis buscaron "el crimen dentro del mismo crimen" 25 . No sólo diseñaron la muerte sistemática sino que se esforzaron en acabar con toda prueba que evidenciara el asesinato en masa perpetrado. Doble empresa asesina. Destruir la destrucción. Como si nunca hubiera tenido lugar.

Derrida, por su parte, ha desarrollado esta reflexión de la desaparición del testigo a partir de su meditación de la huella como ceniza. Esta es lo queda tras la incineración, el resto después de las llamas pero, a la vez, simboliza la extinción de la extinción en la medida en que su labilidad hace que ésta se pierda y, por lo tanto, se

\footnotetext{
24 "En la polisemia, en verdad, en la homonimia de los verbos creer (creer que esto puede sucede, creer en la palabra de alguien, creer en algo, tantas cosas diferentes pero las más de las veces posibles, verosímiles, por lo tanto, creíbles, y así independientes de la pura creencia), yo insistiría sobre esta otra creencia, la creencia por excelencia -que no es posible más que creer en lo imposible. El milagro sería del orden de la pura creencia" (Derrida, J.: La contre-allée (con C. Malabou). Paris, La Quinzaine littéraire-Louis Vuitton, 1999, p. 147).

25 Vidal-Naquet, P.: Les juifs, la mémoire et le présent. Paris, La Découverte, 1991, p. 416.
} 
destruya para siempre la destrucción de la que es testimonio. La ceniza, dada su naturaleza efímera, arruina la posibilidad de testimoniar de la incineración misma. Olvido de todo olvido. La ceniza, pues, pasa por ser "la figura de aquello de lo que no queda ni siquiera ceniza en cierto modo. No queda nada de ello" 26 .

Dado el carácter personal del testimonio, su destinatario carece de acceso a aquello que le es contado; no participa de la vivencia del otro. No hay experiencia para el testigo del testigo. La relación con el otro queda así cortocircuitada, rota; es una relación sin relación. El otro está separado como un secreto. Una interrupción que no es negativa sino que es, ante todo, la posibilidad de que lo otro sea otro. Que el motivo de presencia le esté vedado al otro del testigo no implica que le pertenezca al testigo pues aunque hable en presente, aquí y ahora, en este instante, ante los demás, lo hace de unos hechos que ya no le son presentes, que forman parte de su memoria, que sólo puede rememorar. Por todo ello, a pesar de la comunicabilidad del testimonio, en el fondo permanece impresentable e inaccesible al oyente. Silencioso. El testimonio es siempre secreto. Por mucho que se diga el secreto, éste no pierde su radical privacidad. Que el testimonio desvele un secreto (secretum: "apartado", "separado", "alejado", "escondido") no conlleva que, al manifestarlo, sea expuesto en su epifanía. Decir el secreto no es mostrarlo. El secreto del testimonio es que continúa siendo secreto aún después de ser testimoniado. El secreto que forma parte del testimonio convive, a su vez, con su publicidad o fenomenalidad. No puede haber testimonio que sea secreto: testimoniar "es siempre hacer público"27. No se puede, pues, pensar el testimonio más que desde la aporía insuperable que nos obliga a poner juntos el secreto y la publicidad.

Por otro lado, la verdad ejemplar y singular del testigo apela a una universalidad pues cualquiera que estuviera en su lugar corroboraría una por una cada una de sus palabras. En esa hipotética e imposible situación, el otro no haría sino confirmar el secreto, lo que él percibió o escuchó. Todo testimonio es (ir)repetible. Lo irremplazable del testimonio, su privacidad y exclusividad, ha de dejarse reemplazar. El par singularidad/generalidad queda expresado en la palabra "ejemplo". Un ejemplo se convierte en "un" ejemplo entre otros, uno más, substituible, pero el "ejemplo" es también ejemplar al ponerse como ejemplo, modelo o paradigma, como si se tratase de la idea platónica. En la noción de "ejemplo" (exemplum), como en la de testimonio, se reúnen los significados de original e imitación. Singular y universal son dos predicados que conforman todo testimonio.

Aunque un testimonio sea singular debe ser repetido infinitas veces. Sin repetición no hay testimonio. Aquel que declara ante el otro, promete, aun sin ser explícito, ofrecer de nuevo, ad aeternitatem, el mismo testimonio. Una lógica análoga encontramos en el funcionamiento de la firma que requiere, para su validez, una

26 Derrida, J.: Points de suspension. Entretiens, ed. cit., p. 405.

27 Derrida, J.: Demeure. Maurice Blanchot. Paris, Galilée, 1998, p. 32. 
contrafirma, una reafirmación de la firma. Ahora bien, si esta iterabilidad o repetición es un atributo inseparable del testimonio hasta el punto de que un testimonio irrepetible es una contradicción, la iterabilidad arruina el valor del testimonio pues, ¿en qué se convierte un testimonio cuando se dice de modo mecánico, cuando se despliega maquinalmente?

Junto a la singularidad y universalidad, el testimonio es irreductible a la ficción, al simulacro o a la mentira; no obstante, un testimonio que no pudiera verse afectado por la mala fe, del que se supiera sin género de sospecha de su veracidad, se perdería como testimonio. Lo que constituye una amenaza para el testimonio, el riesgo de lo peor, es también su suerte, su condición de posibilidad. El testimonio se ve así asediado por el perjurio.

Como finalmente no hay prueba para el testimonio, pues de haberla se anularía, no hay forma humana de saber si se dice la verdad sinceramente, si el testigo es veraz en su declaración. Esta insuficiencia esencial abre las puertas a que el perjurio o falso testimonio, que no debe confundirse con un testimonio falso, se cuele en la noción de testimonio. La distinción entre perjurio y testimonio falso consiste en que puede comunicarse algo que no se corresponde con la realidad sin que, por ello, haya intencionalidad o voluntad de engañar. Si supiésemos a ciencia cierta que el otro miente, desaparecería el testimonio y la confianza básica que implica. Ninguna máquina de la verdad podrá probar, en el sentido objetivo de la prueba, de la certeza objetiva, que hubo mentira, que alguien mintió.

6. Decíamos al comienzo del artículo que el fin que nos proponíamos era tomar la figura del testimonio como criterio de la deconstrucción de la metafísica. Si el punto de partida era constatar la indiferencia de la filosofía hacia el testigo, la hipótesis con la que trabajábamos era que, a pesar de este desdén, el testimonio forma parte (no sólo) de la filosofía, es decir, que no hay palabra que no presuponga un testimonio implícito, supuesto, exigido: "el testimonio que es siempre un acto que implica una promesa o un juramento performativo y que constituye el elemento, el médium de todo lenguaje, incluido el lenguaje constatativo"28.

El tipo de creencia que afecta al testimonio es de carácter inaugural. Con independencia de qué prometamos, de cuál sea la promesa concreta realizada, hay una promesa supuesta en cada acto de palabra. Una creencia que Derrida considera "sin dogma y sin religión, irreductible a toda institución religiosa, o implícitamente teocrática" 29 , además de ser el asiento del contrato social, de la vida en sociedad. Derrida se refiere a una fe primera, pre-religiosa, desvinculada de la religión, y que hace posible la relación con el otro, una relación posible en tanto que suspendida. Allí donde hay desconexión hay lo otro, lo otro tiene alguna posibilidad de ser. El

28 Derrida, J.: Histoire du mensonge. Prolégomènes. Paris, L'Herne, 2005, p. 89.

29 Derrida, J.: Voyous. Paris, Galilée, 2003, p. 211. 
fundamento del vínculo social, antes de cualquier pacto o compromiso fáctico, más acá de lo que las teorías contractualistas puedan aportar, es una cierta desvinculación social. Esta interrupción, este cortocircuito, el hecho de que el otro no tenga acceso a mi fuero interior, la falta de una mostración intuitiva, el abismo entre las conciencias, la oscuridad de una 'luz natural', posibilita la mentira que reúne dos condiciones: en primer término, exige un acuerdo básico en el lenguaje, es decir, que comprendamos las palabras que nos intercambiamos, que el otro me entienda como yo me entiendo a mí mismo. La mentira necesita una mínima precomprensión de las palabras. Deben tener los dialogantes suficiente competencia lingüística. No puedo mentir a quien desconozca lo que le digo. En segundo término, la mentira presupone como punto de partida la veracidad, que no hay que confundir con la verdad objetiva. La veracidad hace referencia a la intención de no engañar o de no ser engañado. Para engañar al otro, éste debe dar por supuesto que no lo voy a engañar. Una mentira o perjurio que nunca se podrá excluir.

En un breve texto, "Sobre un presunto derecho a mentir", en respuesta a Benjamin Constant, deja anotado Kant que "la veracidad es un deber que ha de considerarse como la base de todos los deberes fundados en contrato" 30 . El deber incondicional de veracidad se sitúa por encima de los intereses particulares, aunque mintiendo se evitase una flagrante injusticia. Kant excluye de la mentira toda utilidad, el cálculo de un beneficio, lo que se llama la mentira piadosa. A juicio del filósofo de Königsberg, los efectos que se deducirían de institucionalizar el engaño serían tan desastrosos que excederían, con mucho, el perjuicio concreto que pudiera causarle a una persona. Lo que está en juego en la mentira es la existencia misma del orden social. Una sociedad fundada en el engaño arruinaría la convivencia, de ahí el celo extremo que pone Kant en defender la veracidad como pilar del vínculo comunitario. La universalización de la mentira tendría como consecuencia la pérdida de la confianza en el otro, requisito éste para el entendimiento. Es por ello que ser veraz tiene una dimensión absoluta e innegociable en la filosofía de Kant.

Según esta veracidad tácita, cada vez que me dirijo al otro, en cuanto abro la boca para decir lo que sea, por ejemplo, "está lloviendo", estoy prometiendo decir la verdad, ser veraz en mi declaración. Esto significa que "la promesa es el elemento mismo del lenguaje" 31 . Hablar es prometer. Por ello, con independencia del análisis etimológico del testigo/testimonio, testis/superstes, de su historia y evolución, de su emergencia política en un contexto determinado ${ }^{32}$, está la fe jurada, el crédi-

30 Kant, I.: "Sobre un presunto derecho a mentir" en En defensa de la Ilustración. Barcelona, Alba, 1999, pp. 395 - 396.

31 Derrida, J.: "Une certaine possibilité impossible de dire l'événement" en AA. VV.: Dire l'événement, est-ce possible? Paris, L'Harmattan, 2001, p. 107.

32 Annette Wieviorka, especialista en la historia del genocidio, en su iluminador título L'ère du témoin, analiza la evolución que habría sufrido la figura del testimonio en el contexto del exterminio nazi. La primera conclusión a destacar sería que el testimonio como medio de expresión se enmarca en el acon- 
to o la confianza ciega hacia el otro. En la medida que esta promesa me compromete ante el otro, una cierta performatividad está implicada en la palabra dada al interlocutor. El simple hecho de empezar a hablar entraña el compromiso de concluir la frase. Antes de pensar la responsabilidad en términos de libertad individual, desde que decido hablar estoy comprometido con el otro, me responsabilizo ante él. En cada palabra se escucha un 'créeme', 'te digo lo que creo', 'seguiré hablándote hasta que finalice mi discurso'; late una promesa de decir la verdad, una voluntad de no engañar a aquel a quien me dirijo. Esta estructura fiduciaria, secreta y privada, hace improbable demostrar que hubo mentira, es decir, que el que hablaba tenía intención de engañar, que no creía en aquello que expresaba, que su intención era inducir a error al otro, que estaba cometiendo perjurio. Como la mentira es un episodio posible, siempre presente y nunca demostrable, escribe Derrida que "comienzo siempre por pedir perdón cuando me dirijo al otro"33. Un hipotético perjurio amenaza a todo discurso y el engaño ronda mis palabras. Querer erradicar la mentira sería renunciar, al mismo tiempo, a la oportunidad de la verdad. La promesa de decir la verdad es más vieja que todas las promesas singulares que podamos realizar. Lo que se promete en esta promesa originaria o (archi)promesa no es nada concreto, aunque comprometa al que la profiere en una ligazón absoluta con el otro. No hay medio de comprobar el cumplimiento de esta promesa. Jamás podrá revelarse el fraude. Por eso, es propio de esta promesa que quede incumplida para siempre, cumpliéndose así.

En otros textos, Derrida conecta esta promesa con la figura del sí incondicional -uno de los problemas quizás más difíciles de la deconstrucción derridiana pero, a

tecimiento de la Shoah. En su estudio establece tres etapas en el devenir del testimonio. La primera fase incluye, por un lado, las narraciones de todos aquellos que no habrían sobrevivido a la destrucción y que encontraron en la escritura la manera de legar a la posteridad su verdad y, por otro lado, las narraciones publicadas en vida tras el final de la guerra y que, como característica compartida, fueron desoídas por el público. Habrá que esperar hasta el 'caso Eichmann' para que el testimonio adquiera una tonalidad política, hasta entonces inexistente. Este proceso judicial, desarrollado en Israel después de ser secuestrado Eichmann en Argentina, supone un giro radical en la construcción de la memoria del genocidio y con ella en la noción de testimonio. Comienza "el advenimiento del testigo" (Wieviorka, A.: L'ère du témoin. Paris, Hachette, 1998, p. 82). El testigo abandona el espacio privado y su palabra cobra una dimensión social. Son los propios supervivientes los que hablan de la catástrofe del pueblo judío. La tercera y última etapa se fecha a partir de los años 70 y se define por una democratización del testimonio, favorecida por el papel difusor de los medios audiovisuales, sobre todo, la televisión y el cine con series o con películas de enorme éxito como Holocausto y la Lista de Schindler. Asistimos a una verdadera pasión por recoger miles de testimonios de gente anónima, como ha realizado la fundación de Spielberg.

A través de este repaso a vuela pluma, de la mano de Wieviorka, hemos querido señalar que la reflexión derridiana acerca del testimonio, en su caso desde la filosofía, podría interpretarse como un signo más de la presencia de una cuestión de corta edad, nacida de las cenizas de los hornos crematorios, y que se ha convertido en un imperativo ético para muchos supervivientes.

33 Derrida, J.: Papier Machine, ed. cit., p. 83. 
la vez, más determinantes en su obra. No en vano confiesa que "desde hace mucho tiempo la cuestión del si moviliza o atraviesa todo lo que me esfuerzo en pensar, enseñar o leer" 34 . Un sí que tiene que ver con esta aquiescencia inaugural que me relaciona con el otro. Debe quedar claro que todo intento de explicación del sí presupone el sí. Por ello, aquel metalenguaje que quisiera hablar de este sí se vería requerido por dicho sí.

En primer lugar, sí es una respuesta. Cuando alguien dice sí está contestando a una interpelación venida de otro. En tanto que este sí es una respuesta y, en consecuencia, segunda, entonces este valor del sí presupone lo otro. Esta modalidad del sí-respuesta le sirve a Derrida para cuestionar el privilegio acordado a la pregunta por la filosofía. Habría "un sí que abre la pregunta y se deja presuponer siempre por ella" 35 , es decir, que "antes" de la pregunta, con una anterioridad no temporal, hay un sí sobreentendido, una aquiescencia al otro, una aceptación básica, una heteronomía insuperable. Frente al cliché del filósofo como hacedor de preguntas, siempre produciendo nuevos horizontes, Derrida habla de un sí previo a la interrogación, un si pre-interrogativo y, desde la perspectiva filosófica, pre-filosófico: "la pregunta no es la última palabra en el lenguaje. Primero porque no es la primera palabra. En todo caso, antes de la palabra, hay esta palabra sin palabra que nombramos $s l^{\prime \prime 36}$.

En segundo lugar, sí toma la forma de un compromiso o de una promesa. Cada vez que decimos sí estamos suscribiendo algo. Aquí radica el carácter afirmativo de la deconstrucción. Si nos fijamos en el significado del testimonio vemos que lo que nos dicta no es testimoniar lo creíble, razonable, asumible sino lo increíble, inimaginable, imposible. Un testimonio posible sólo lo es en tanto que imposible. A la vez, este sí afirmativo guarda dentro de él la promesa de una repetición: "el sí exige a priori su repetición, su puesta en memoria, y que un sí al sí habite la llegada del primer $s i$, que no es simplemente originario. No podemos decir sí sin prometer confirmarlo y acordarnos de él, conservarlo, refrendarlo con otro sí, sin la promesa y la memoria, la promesa de la memoria" 37 . Una repetición indisociable de la promesa ya que una promesa promete ser mantenida en el futuro. La iterabilidad se nos revela como la condición de cualquier promesa. Una repetición que hemos visto trabaja igualmente en el testimonio. Aquel que testifica promete refrendar cada una de sus palabras una y mil veces. Siempre. Este si que tanto interesa a Derrida libera el espacio para que ocurra algo, por ejemplo, un testimonio. Un si que "abre la acontecibilidad de todo acontecimiento" 38 que se presenta, sin ser jamás presente. Mientras que las religiones del Libro llenan y dotan de contenido ese ámbito,

\footnotetext{
34 Derrida, J.: Ulysse gramophone. Deux mots pour Joyce. Paris, Galilée, 1987, p. 108.

35 Derrida, J.: Psyché. Inventions de l'autre, ed. cit., p. 642.

36 Derrida, J.: Heidegger et la question. Paris, Flammarion, 1990, p. 115, nota 1.

37 Derrida, J.: Ulysse gramophone. Deux mots pour Joyce, ed. cit., pp. 136-137.

38 Derrida, J.: Psyché. Inventions de l'autre, ed. cit., p. 648.
} 
Derrida mantiene la promesa en tanto que promesa. Esta apertura a la alteridad, libre de toda verdad soteriológica, que recibirá el nombre de "lo mesiánico sin mesianismo" 39 quiere ser fiel a esta estructura del sí. A diferencia de las religiones que saturan esa apertura hacia lo otro, cercando el horizonte hasta domesticarlo, Derrida la mantiene virgen, incólume, desértica, para que esa alteridad radical tenga alguna oportunidad. Como si las religiones retrocedieran ante la indeterminación que implica lo otro, como si sintiesen un pánico atroz ante la venida abrupta del acontecimiento, del arribante absoluto. Y con razón.

El testimonio es otra de las figuras de ese pensamiento de lo imposible sobre el que tan incansablemente trabajó Derrida. El testimonio, en tanto que intestimoniable, testimonia, más allá de la idea de posibilidad, credibilidad o probabilidad, desbordando el marco de lo que se pueda testimoniar, de lo otro radicalmente otro, del acontecimiento como venida inesperada, de una alteridad incalculable e inanticipable. Si sólo hay testimonio allí donde es imposible, ¿quién podrá jamás decir que testimonió?, ¿por qué, en cualquier caso, es preciso que haya testimonio - siquiera como intestimoniable? Porque responder a la llamada de incondicionalidad que prescribe el testimonio es la única manera de que lo otro acontezca.

39 Derrida, J.: Spectres de Marx, ed. cit., p. 124. 